\title{
Research on the Diffusion of Network Public Opinion for Emergency in the Network Media
}

\author{
Xie Xiaotong ${ }^{1, a}$ \\ ${ }^{1}$ School of Digital Media and Design Arts, Beijing University of Posts and Telecommunications, \\ Beijing 100876, China.
}

a13269475800@163.com

Keywords: Network public opinion; Public opinion for emergency; Network media

\begin{abstract}
With the development of the internet, the network public opinion has deeply involved in real life which arouses government, scholars and public concern. This paper firstly summarizes the connotation and characters of network public opinion for emergency, then analyzes the transmission mechanism of public opinion for emergency from the external and internal perspectives. In the third part, the effects of network media in the diffusion of public opinion for emergency is discussed.
\end{abstract}

\section{Introduction}

With the popularization and development of the internet, the ways of people obtain information have been deeply changed. Nowadays, people can use their mobile terminals to access internet wherever and whenever, and can express their opinions, emotions and attitudes much more convenient and frequent. However, this trend results in moralization, extensification and complication of network public opinion about emergency[1]. Network public opinion about emergency refers to the sum of public opinions, public emotions and public attitudes towards a certain event through network, whose characteristics entail instantaneous occurrence, latent subject, communicative interaction, content richness and group polarization[2]. Various public emergencies have become a prominent issue for affecting of our social stability, in this environment, network society and real society is deeply interconnected[3]. The emergency network public opinion evolution process can be found in all kinds of network media, such as web news, forum and blog, which brought unprecedented pressure for government to manage the emergencies and control its influence. These phenomena arouse the government official, scholar and public concern, and research on the diffusion of public opinion for emergency in the network media can help to figure out the evolvement rules of public opinion and help government to manage it.

\section{The connotation and characters of network public opinion for emergency}

The connotation of network public opinion for emergency. With the development of the electronic network technology, the Internet has impact and changed the basic environment of social public opinion, a new field of public opinion based on the internet circumstances has come to realize. Network public opinion is an expression of public opinion through the Internet. In our daily life, some of the common event public opinion have formed a propensity of emotion or opinion just because the Internet communication factors. For now, there are two levels of public opinion, the reality public opinion and network public opinion, those two have the same essence, all means to people's attitude or wishes toward social problems. While network public opinion is the public opinion formation that spread through Internet media forms.

In general, the network public opinion is the virtual reflection of public opinion in real world, is the combine and communication of the netizen's emotion, opinion and attitude to public event or real life in the internet. the network public opinion for emergency refers to the sum of opinion, emotion and attitude which published through all kinds of internet platforms after the event, the opinions often related to political, economic, and society, and have tendency.

The characters of network public opinion for emergency. Network public opinion for emergency is a special form of network public opinion, due to its communication media mainly in 
internet space, so besides its general characteristics of social public opinion, it also has its distinctive characteristics.

(1) Happened real-time. The most significant character of network public opinion for emergency which is different with general emergency network public opinion its happening and diffusion is real-time. On one hand, emergency itself is happened very quickly and unpredictable, which makes government, social media and general public have difficult to make correct and comprehensive judgment and emergency response. On the other hand, the internet is a completely open space which expands the channel to communicate and judgment. Its high efficiency and interactive make the real-time of network public opinion for emergency possible. all the discourse space

(2) Anonymous of identity. The internet media provides a virtual network space network ID for each individual regardless of gender, age, occupation, race and social status. Therefore, the subjects of public opinion can internet users can release information, opinions and discussions without warry the external pressure of strong opinions groups, social role expectations and the constraint of social ethics and standard.

(3) Interactivity of communication. The Internet has become an important place of public interest expression, ideas communication and emotional catharsis. The emergency network public opinion has become the new express and reflect of people's freedom of speech. The interactivity of communication can produce cluster effect in the interaction of the public opinion, which make the emergency more complicated.

(4) Richness of the content. Nowadays, the Internet has become an independent source of news public opinion. With the expanding of network, the network public opinion for emergency is becoming vaster. The events and social problem involves all aspects of the society; especially events can arise resonance in the general public.

\section{The diffusion of public opinion for emergency in the network media}

The diffusion of public opinion is a multi-factor interactive dynamic process, the interaction and change between various elements drives the evolution of public opinion. In this part, the transmission mechanism of public opinion in the network media and the role of network media in the spread of public opinion will be discussed.

The network media, also known as the new media, is the fourth media after the newspaper, broadcast and TV program. The network media is the platform of publishing information via the Internet, in its information release business, a big part of content is the news information and other services specifically meet the needs of public. The diffusion of public opinion for emergency in the network media involves the governments, the network media, the opinion leader and the social public. It also influenced by external environmental factors.

The transmission mechanism of public opinion for emergency in the network media. From the collection of the emergency public opinion to the final transfer of information, there exists many links in the communication process, which would influence the information diffusion of network media. This part will analysis the transmission mechanism from the external environment and system internal perspectives.

(1) The external environment factors. The most significant external environment factor that affect the spread of the network public opinion for emergency is the system interference noise. Public emergency is urgency, uncertainty, big hazard, information magnification, group polarization and difficult to control, etc. those features provided soil for the existence of system noise. Specifically, because of the urgency and uncertainty of the events, make the information stream filled with confusion of symbols and the uncertain information. In this circumstances, the normal information transmission system is broken, the system deviates from the equilibrium state. The normal information dissemination way and the mechanism of environmental factors are being impact, or even abandoned. The chaos of symbol and the uncertainty of meanings will cause a huge information gap, which contributed to the complexity of the propagation of information. The spread of rumors, misunderstanding and questions in the external environment system will lead to the disorder of transmission structure and system. Moreover, the quickly events report and publish of 
media in emergency situations further exacerbated the possibility of information distortion.

(2) The internal system factors. The internal factors of network public opinion in public emergency includes stakeholders, government management departments, network media organizations and audience. Their interaction and mutual influence drive the development of network public opinion.

(a) Stakeholders. The information published by stakeholders on the network information is very subjective and emotional. In order to fully express their own interests appeal, stakeholders usually from their own standpoint, publish various events into the internet that they think inequality or aggrieved, look forward to media attention in order to maintain their own rights and interests.

Under normal circumstances, this kind of movements will make the information released by stakeholders very controversial and emotional, and become the hot point in network and cause for concern.

(b) Governments management departments. Government management departments have legal status and ability to deal with social public affairs, it is the network public opinion for emergency crisis manager[4]. The information in the network released by government has the characteristics of accurate, authoritative and objective. Government should publish the main information of the emergency in the first place, then released the verification information, government response measurements and preventive measures, and prepare for the subsequent release according to the treatment situation of events.

(c) Network media organizations. In the public emergency, government usually requires media to cooperate, report the emergency in rolling news, in order to effectively convey the official information of the crisis event. In the process of reporting, network media often find their own point of view and pay attention to derivative news.

In the reporting of the emergency, the network news media which based on the traditional news media has absolute advantage on the crisis information acquisition, calculation and release. The emergency information processing of the network news media is shown in figure1. The network news media will send the professional editorial team to the scene of event to gather information. Some powerful network news media supervise the online public opinion information and track information sources by using public opinion monitoring system. The network news media also need to examine and verify the information they achieve from various kinds of information flow and send it to management apartments.

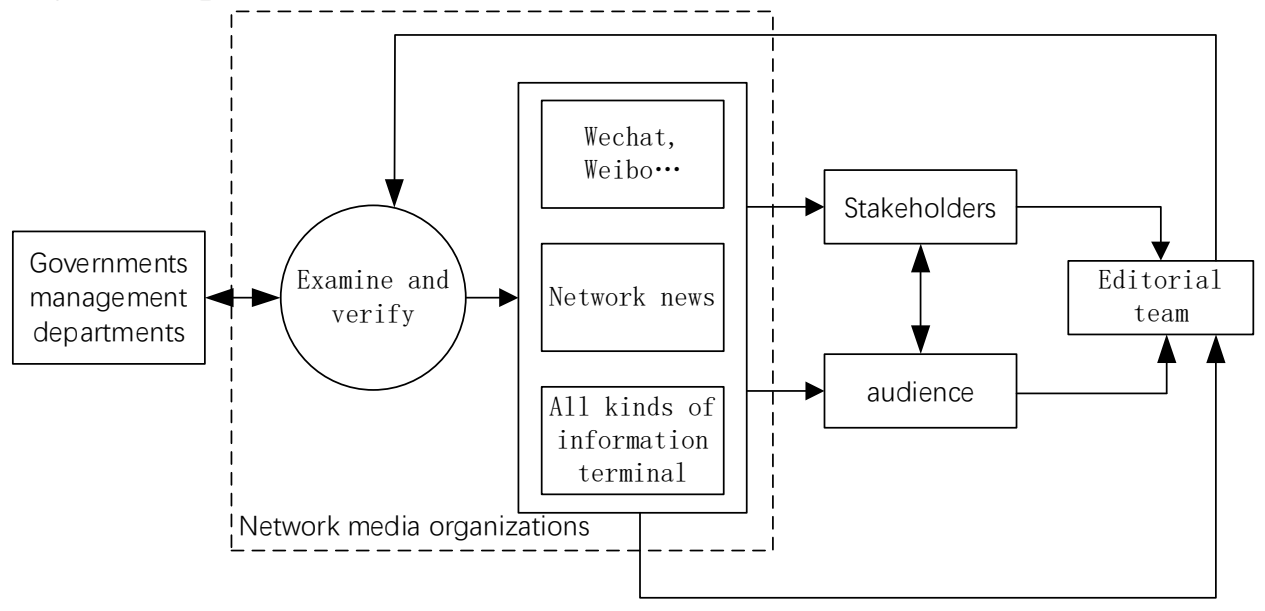

Fig. 1 The emergency information processing of the network news media

(d) Audience. The audience of public opinion for emergency is mainly the net citizen. The net citizen is an important factor of affecting the development of public emergency, their irrational will leads to the crisis of public opinion, while their rational can resolve the crisis. According to the different type of public emergency, the netizen usually takes the onlookers, speech support or practical support strategy.

The effects of network media in the diffusion of public opinion for emergency. The network media plays a positive role during the reporting of public emergency. The network media can help 
filtering the bad information on the internet to guarantee the accurate and fast delivery of network information[5]. The interaction of network media and public opinion also can help government and media to handle the develop momentum of public opinion, find potential social problems, and guide public opinion to the benign direction. However, the over-consumption of public emergency on network media can also produce some negative effect, including the homogeneity of reports and the amplification effect which interferes management departments to investigate.

\section{Conclusion}

The network public opinion for emergency is a common social phenomenon, is the channel of social public to express personal emotions, opinions and attitudes most of which is irrational and easy to trigger network crisis. Therefore, it is necessary to implement government monitoring mechanism of emergency network public opinion, mange the network public opinion through government constraint. The main purpose is to maintain and ensure the controllability and rationality of the network public opinion for emergency.

\section{References}

[1] Mendoza, M., B. Poblete, and C. Castillo. Twitter Under Crisis: Can we trust what we RT? in Social Media Analytics, SOMA, KDD workshop. 2010.

[2] Rosenthal, U., A. Boin, and L.K. Comfort, Managing crises: threats, dilemmas, opportunities. Bureau of Justice Statistics, 2001.

[3] Cochran, J.K. and M.B. Chamlin, can information change public opinion? Another test of the Marshall hypotheses. Journal of Criminal Justice, 2005. 33(6): p. 573-584.

[4] Schultz, F., S. Utz, and A. Göritz, Is the medium the message? Perceptions of and reactions to crisis communication via twitter, blogs and traditional media. Public Relations Review, 2011. 37(1): p. 20-27.

[5] Coombs, W.T. and S.J. Holladay, Further explorations of post-crisis communication: Effect of media and response strategies on perceptions and intentions. Public Relations Review, 2009. 35(1): p. 1-6. 